\title{
Color Study of Chinese Traditional Architecture in Sui and Tang Dynasties
}

\author{
WANG Xiaoguang \\ Nanjing city Vocational College,Nanjing 210038 ,China \\ wangxiaoguang@126.com
}

\begin{abstract}
Keywords: Sui and Tang dynasties, color level, architectural color, wall painting, Foguang temple, Nanchan Temple

Abstract. Sui and Tang dynasties were the important period of the maturity of the architectural development in our country. Color applied in the building design of architectural had a profound influence on future generations. This paper analyzes the external color of the architecture and the interior color of the wall painting, as well as the sculpture color, from the architectural color system of Sui and Tang dynasties, to the existing Foguang temple and Nanchan Temple as the main research objects, and sums up the coloring characteristics of buildings, puts forward the color change and development of the Sui and Tang dynasties.
\end{abstract}

\section{Architecture color system and cultural concept in Sui and Tang dynasties}

The Sui dynasty ended China's long-term of war split in the bureau of the northern and southern dynasties, in which the economy and culture got fast development, especially in the Tang dynasty, the national stability and social economic prosperity accelerate the cultural communication with Tubo, Dali and other ethnic minorities, and spread to the Korean peninsula, Japan and other countries. Sui and Tang dynasties is the period that the China's ancient architecture becoming mature. And architectural color as one of the building elements also has much change and development in Sui and Tang dynasties, and has a far-reaching influence on future generations.

The use of building color in Sui and Tang dynasties, on the whole, is the continuation of color symbolism( five colors and five elements) in Qin and Han dynasties: east to green, west to white, south to red, north to black, and the square central is the soil to yellow. In addition to the influence of five colors and five elements, the influence of Confucian culture and Taoist culture on color is also very big, especially the Confucian culture. Confucian culture has been adopted by all previous dynasties rulers since Han dynasty, five colors and five elements also continue to use the concepts of color grade in Confucian culture.

Tang dynasty established the idea of yellow centering in all the colors, yellow was the color of the royal dedicated, yellow the most noble color can only be used by the royal, the rest of the subjects must not use, The coloring rules also inherited by offspring. Tang dynasty specified that the palace temple should use yellow and red, red, green, government officials use blue and all the other colors, citizens only use no color level such as black, grey and white, which was regulated in the form of law, such as the Repair Decree issued in the Tang dynasty, ruled the grade and the shape of construction of architecture. 


\section{Nanchan temple in the Mount Wutai}

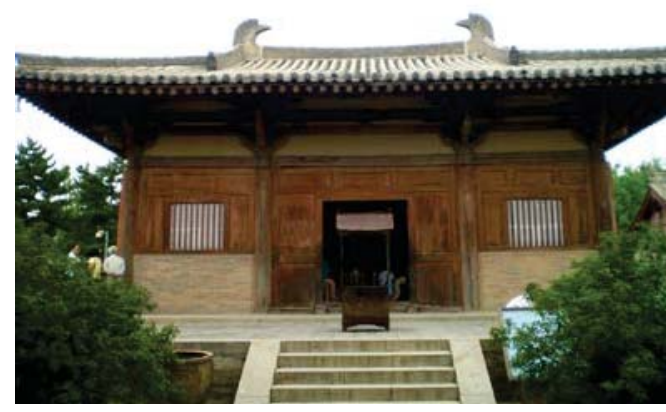

P1

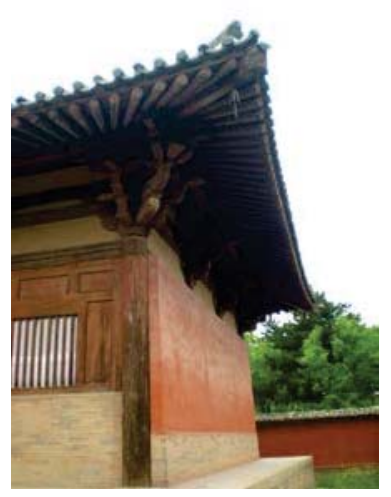

P3

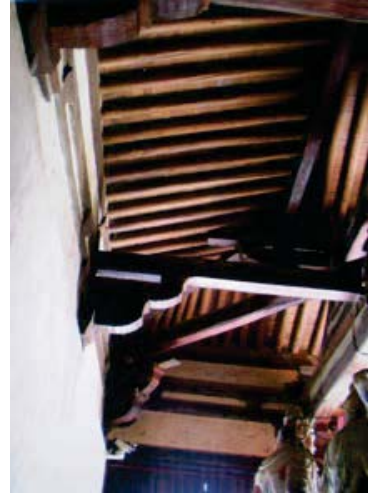

P2

Nanchan temple is located in the deal of Wutai mountain in Shanxi Province in China. It is a small mountain village temple with about 3000 square meters. Temple faces south, is a quadrangle courtyard mainly composed of the gate, sub temples in east and west and the big Buddha hall (see the picture 1 and 2 and 3). There are only six existing halls in nowadays, among which the north of the main big Buddha hall has three rooms in its wide and deep, is the most complete and the oldest wooden structure existing in our country of the tang dynasty, is also the oldest wooden structure in Asia

Buddha hall in Nanchan temple was reconstruction on the third year of Tang Jian-zhong (AD 782), more than one thousand two hundred years ago. Buddha hall consists of roof, truss and stairs three parts, respectively for the white and gray, the red and the black three color gray. Construction of base station is square, the area of which is about the size of the account for almost half a yard, base stations and the steps are made by white and gray stone. Door and window structure as well as pillars in red of the Big Buddha hall adopt the commonly used way in the Tang dynasty, the wooden frame.

The facade wall of Big Buddha hall uses brick, brick wall uses lime plaster. In order to coordinate with scarlet red facade windows and doors, the other three walls in the Big Buddha hall adopt the practice of "red wall", the walls about $30 \mathrm{~cm}$ from ground use lime plaster with scarlet in the middle part, the beam wall is the practice of using lime plaster so as to make the consistent color and facade. Overall the external wall is decorated in red and white two colors, simple and clean color use but with great color contrast showing the heroic momentum of Tang dynasty.

Big Buddha hall' s roof eaves tiles laid, eaves tiles are black brick, its texture is more closely and the surface polished is relatively smooth. According to the literature this black brick is often used in palaces and temples in Tang dynasty architecture. According to records, while the building was repaired, sea beast is later added when offspring repairs, but also according to the form of Tang dynasty. The existing gray and black may not one hundred percent to their original state of the Tang dynasty. Big Buddha hall may use colored glaze in Chiwei acording to the building way of the contemporary some speculate.

Exterior color of Big Buddha hall building is mainly composed of these three colors: red, white, black, concise color using and lively contrast, skilful building process, without overmuch adornment, quaint very modest. External scarlet of warm color and blue sky form a strong contrast of changes in temperature, black roof and white wall in the whole shade play good excessive and coordination role, showing us solemn but not depressive, reflects the majestic in Tang dynasty. 


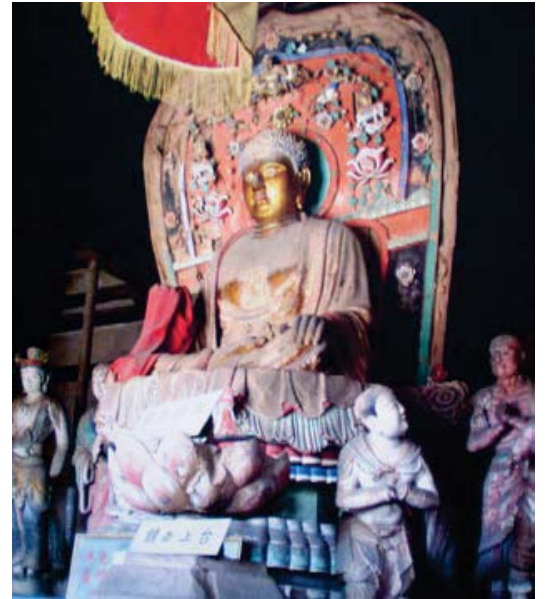

P4

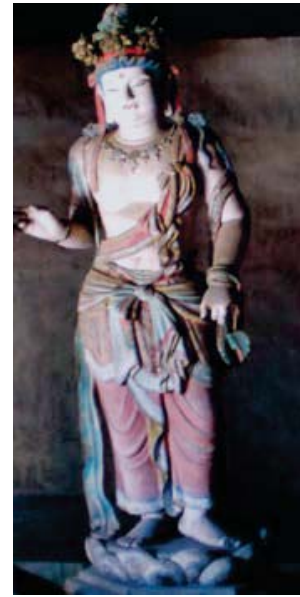

P6

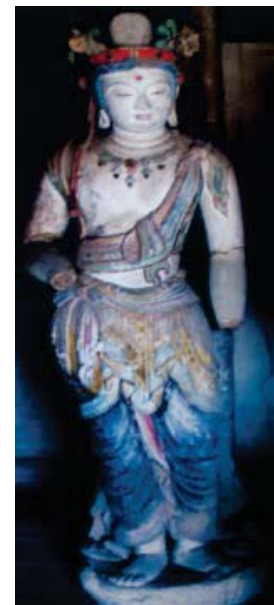

Big Buddha hall also preserves a dozen of Buddha, all are Tang dynasty treasures with moderate statue of proportion, facial fullness, expression, and are very similar to the statue in Dunhuang Mogao Grottoes of the Tang dynasty. Colored drawing or pattern colors include six kinds: red, yellow, blue, green, black, white. The above three pictures are the statue giving us the feeling of generous, thickens, sedate and pure.

\section{The Foguang temple in the Wutai county}

Foguang temple is located in Wutai county of Shanxi Province in China, 32 kilometers northeast of the mountainside. The whole temple is divided into three courtyards, compound ladder shaped, strewn at random discretion priorities. Temple contains a mountainside of the east hall, Manjusri temple, mountain gate, king temple, Jialan temple and etc. One of the main hall the east hall is the only one of two buildings of the Tang dynasty, located the highest point in the temple magnificence.
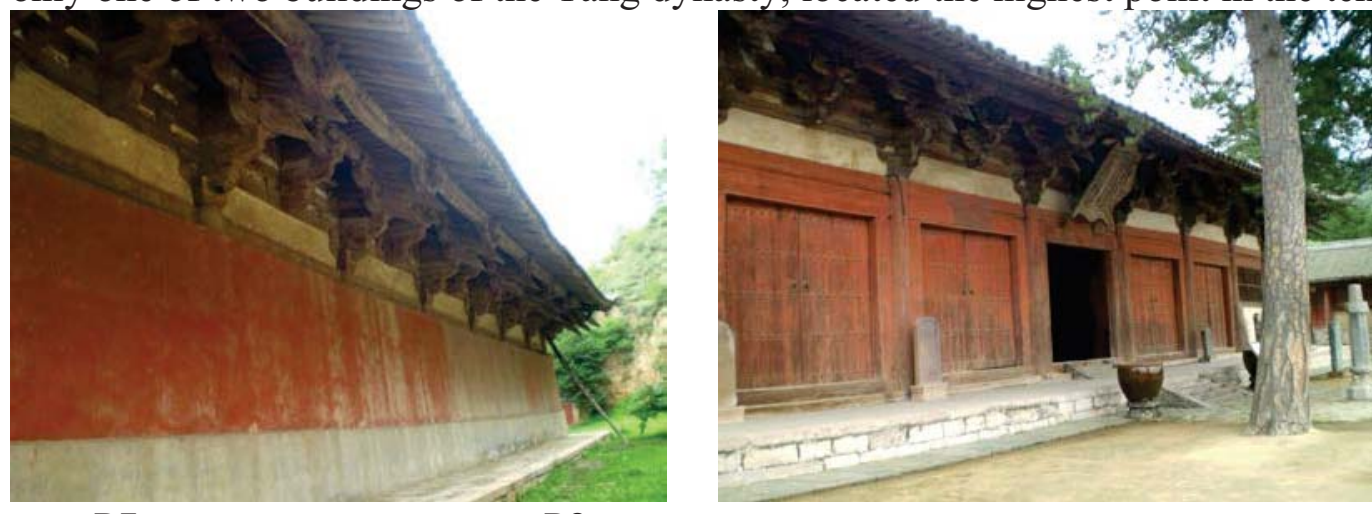

P7

P8

East temple was rebuilt in AD 857, the eleventh year of Tang xuanzong, the width is seven and depth is four, the eaves far-reaching, is the typical tang dynasty architecture. The base 1, steps and corridor of the east hall use stone strip for white and gray brick, this is in line with the south temple. Facade of the door frame and door plank and south temple besmear brush same scarlet, the wall use lime plaster same as the hall of wooden doors and windows. Cylinder components are adopted such as red face, the facade color use is very simple, only the two colors, red and white contrast, giving people very quaint sense.

Other three walls of the east hall on the surface also adopted the practice of "red wall", the color is very bright and concise, construction of bucket gong frame wooden structure from now basic presents is a grain of wood color, but according to the above trace of the residual speculation, it should use color decorative surface, had all faded now. Thus the building columns, doors and windows, walls and so on all use red besmear to brush, and may impose such as local wooden framework such as stone colored drawing or pattern, the whole building is made up of white and red color, coloring and concise comparative and intense, the whole is a warm color. 
At the top of the beams, East hall has the ceiling divided into open frame beams and hidden two parts. On the local wooden structures such as beams and arches there are about 700 or 800 dovetail paintings, painted statues, such as lotus pattern. The main color pattern are red and white, there are also colors such as green, green, red. So we can see that at that time, building painting has already started to use more colors, and the cool colors such as green and blue color also have started to use in the architectural colored drawing. The use of color and the colored patting is very close to the expression in the "Ying Zao Fa Shi" of Song dynasty.

Interior walls are white, it can make indoor brighter, and painting in the local metope about a dozen square meters, the content in the murals are about Buddhist stories. Murals in the overall picture is turquoise color, images of major of ochre and green stone, there are some metal gray color, give people the sense of rich and heavy, this is completely consistent with the mogao grottoes in Dunhuang murals in Tang dynasty. Some use the contrast of changes in temperature, such as, by green color contrast, image lifelike, painting techniques using the method of color shading, give a person the feeling is not flat but very rich and colorful. Murals characters in the woman's woman on the cheek is red, not red flat, but has a gradient from the center to become dizzy are scattered all around, let a person feel rich colors, stereo sense is stronger, is very vivid. On the expression of characters, besides using the black lines, and in scarlet, green stone, ochre, khaki color shading, such not only use the traditional cancel the technique, and also use color shading the characters clothes more elegant character is more stereo feeling.

Through existing legacy of Dunhuang mogao grottoes of the Sui dynasty murals, we can see in the early years of the Sui dynasty frescoes composition was more lively, mostly in red soil composition, its face and body don't use shading just light color, is relatively single, only use a few kinds of color, is simple quietly elegant. By the end of the Sui dynasty, murals had be painted more meticulous, had adopted many black and brown compared with color bright and brilliant color, made the picture messiness. The usage of color is no longer singer, such as green, the original only used a single stone green, but in Tang dynasty used the stone green, blackish green, gray green for different color purity and lightness changes in temperature, let green department had rich color gradation, image more harmonious, more natural transition.

Tang dynasty's national strength, politics, economy, culture and art have reached a peak, mural art spirit grand, color is gorgeous, is the most glorious era of Chinese art. Tang dynasty murals on the basis of predecessors' painting constantly draw inspiration from folk, and in the communication and integration of Chinese and foreign art development to mature gradually, the use of color performance and technique innovation and evolution of the paintings on the walls of this period present a rich and colorful new look, with strong ethnic characteristics.

According to Mr Liu in the Chinese painting art, pigment used in paint murals in Tang dynasty are mainly "azurite, green stone, cinnabar, vermillion, ChuShi, terra rossa, yellow, gamboge, indigo, clam powder, clay, gold foil and ink." Thus it can be seen that in the Tang dynasty murals color used more colorful than before. Clever collocation between mural by color, the same color level use different lightness and pureness to make the painting coordinate transition nature, a large number of shading painting techniques make the color change more subtle and colorful content.

\section{Summary}

The use of color in Sui and Tang dynasties buildings inherited and perfected the past practice formed its own color characteristics. Architecture roof use black eaves tiles as paving, ridge and chiwei use green glazed tile to decorate making the outline of the roof contrast strongly. The palace roof in large area uses green, blue, yellow glazed tile and even three-colored glazed tile. Doors and windows, dou gong, beams and other wooden components in scarlet besmear brushs metope use white basic as well as the practice of "red wall", the steps of the building and base stations use the light-colored stone pavement, building the overall color is rich, comparative and intense, gorgeous and colorful. A large number mural painting and colorful painting as decoration is used in Sui and Tang dynasties buildings, color usage is more colorful. Due to the influence of Buddhism, golden also 
has been used in construction. According to the historical records of the palace buildings in Sui and Tang dynasties, it has already used a lot of precious materials such as gold and silver jade article so as to enrich the composition of the whole building color, and make the building more colorful.

\section{Acknowledgements}

This paper is one of the series of achievements in the study of philosophy and sociology in Jiangsu universities. The name of the project is "Chinese dream", the Chinese traditional architecture color research, project approval number: 2015SJD329..

\section{References}

[1] Wang Xiaoguang, Development of the official building of the Chinese traditional color [D]. Master thesis, southeast university, 2011.

[2] Lu Yingxia, Culture idea and culture of Chinese traditional architectural color characterization [D]. Master thesis, Hal ice industrial university, 2008.

[3] Zhao Yunqi, Theory of the south temple sculpture art [J]. Journal of wutai mountain research, 1987 (06):33-40.

[4] Zhao Enlin, World treasure the Nanchan Temple [J].Wutai Montain research, 2010(01): 49-56.

[5] Ding Gui, Architecture colorful painting in the temple of Foguang Temple [J]. Treasure,2015 (10): 70-85. 